\title{
Research on Images of Cross-Dresser from the Perspective of Androgyny
}

\author{
Shuya Hao, Weili Zi* \\ School of Language and Culture, Beijing Institute of Fashion Technology, Beijing, China \\ Email:120371826@qq.com, *zwlpost@126.com
}

How to cite this paper: Hao, S. Y., \& Zi, W. L. (2019). Research on Images of CrossDresser from the Perspective of Androgyny. Chinese Studies, 8, 92-102. https://doi.org/10.4236/chnstd.2019.83008

Received: June 8, 2019

Accepted: August 20, 2019

Published: August 23, 2019

Copyright $\odot 2019$ by author(s) and Scientific Research Publishing Inc. This work is licensed under the Creative Commons Attribution International License (CC BY 4.0).

http://creativecommons.org/licenses/by/4.0/

\begin{abstract}
From the gender perspective of Androgyny and Camp theory, the images of cross-dressers in film and television or literary works in this paper are analyzed and discussed in terms of the two aspects of cross-dressing culture, including the great revelry and dangerous boundary of Androgyny. The result of the analysis indicates that the study of the Androgyny-a unique aesthetic temperament in cross-dressers, breaks the consistency between male and female in physiological and social gender to a certain extent, blurs the social differences between the two sexes with strict boundary, and increases the public acceptance and tolerance of the phenomenon of "cross-dressing". The discussion of paper can be used for reference in breaking the traditional gender model of dualistic opposition and pursuing gender harmony, which provides a new direction for other scholars for the further research.
\end{abstract}

\section{Keywords}

Androgyny, Camp, Gender, Image of Cross-Dressing

\section{Introduction}

\subsection{The Definition of Cross-Dressing}

Cross-dressing, also called transvestism, refers to wearing the clothes and the ornaments related to the opposite sex in a particular society, thus switching the gender symbol quickly by changing the clothing, and replacing the gender identity at the level of the signifier in an attempt to gain the public recognition of their cross-dressing images. So, the wearer who wears the clothes of opposite sex is named "cross-dresser" or "transvestite". Cross-dressing has been designated to disguise and been acted as a literary metaphor for modern and historical purposes. However, it does not necessarily indicate the radical change in transgender identity. The term "cross-dressing" refers to an act or a behavior, and does not 
attribute to or imply any specific cause of the act. Generally, the transsexual behavior is automatically associated with transgender identity or sexual orientation, fetishism, and homosexual behavior, but the term itself does not imply any motivation.

Today in the 21st century, the phenomenon of cross-dressing seems to be in a state of long-term aphasia, either from the perspective of social public opinion or of cultural studies. As far as the public awareness is concerned, ranging from being kept dark before to nowadays' being overcorrected, the word "cross-dressing" itself has inevitably carried a certain degree of bias. Undoubtedly, the living condition of the cross-dressers is still quite difficult. But, the expressions of cross-dressing are also increasingly diversified.

\subsection{The History of Cross-Dressing}

In Western cultural context, the Cross-dressing first appeared on the stage of drama, and along with the emergence and evolution of drama, cross-dressing also has different stage performances and presents corresponding social and cultural significance. In the flourishing period of drama in ancient Greek, male performers disguised as women by wearing female clothing was a necessary means of technical treatment on the stage of drama, which resulted from the serious imbalance of social rights between men and women. It can be said that the origin of early Cross-dressing was presented in the way of depriving and avoiding women's social identity, indicating a simple and brutal sexual repression in the patriarchal society (Gao, 2004: p. 66). With the drama flourished in Shakespeare's time, the presentation of female images on the stage underwent a great change although women were still isolated from the stage. The women disguised by men on the stage were more perfectly and accurately like women, both in shape, clothing, voice and inner emotional and spiritual expression of female. Although the stage image serves the drama itself, the phenomenon of Cross-dressing on stage, in a sense, also looses the strict boundaries between male and female.

In the oriental cultural context, men in Japanese kabuki performance dresses like women, while women in Japanese kabuki dresses like men including the Nandan - the male actor in Chinese drama, who dresses as what a woman is like, and performs like a woman on stage which, in fact, lubricates the gender barriers between two sexes. Drama performance is like a special channel of communication. The Cross-dressers on the stage not only voice for the female characters in the play, but also for the women who have been forcibly deprived of social rights. The ancient Chinese story of Hua Mulan who takes her father's place in conscription army has been handed down till now. The social demands behind Hua Mulan's female disguise as a man have the same function as the poetry creation in the textual sense of ancient officials in Cross-dressing, both containing the obvious class revolt among them. Cross-dressing is the transformation of identity, thus, the gender transformation of Hua Mulan from object to subject confronts the feudal monarchy, while scholars and officials euphemistically con- 
fide their forbearance and helplessness under the authority of the monarch by comparing themselves to women. The performance nature of cross-dressing itself gives birth to the inner real appeal of each gender group.

In modern times, Cross-dressing has become more diversified and more freely operated. Apart from the theatre stage, Cross-dressing in various social environments has become increasingly diverse and common. For example, various kinds of male and female cross-dressing performances can often create and heighten a very warm stage atmosphere, broadening the audience's artistic appreciations, and as a result, a lot of cross-dressers have emerged, including Cross-dressing artists, transgenders in the LGBT group and those with "female identity" in gay men's relationship, who announce their true inner self by cross-dressing to change their gender. Even cross-dressing enables some Individuals with more pure performance desire to challenge and resist the rigid doctrine of gender aesthetics and gender norms in the popular sense. In a word, Cross-dressing, nowadays, could present itself in various ways, with growing social influence and public acceptance.

\section{Research Theory}

\subsection{Androgyny}

"Androgyny", also called "bisexuality" or "hermaphrodite". When it comes to this word, it is generally first thought of "hermaphroditism"-the biological concept "Androgyny" refers to the combination of masculinity and femininity. In the Western culture, the concept of Androgyny can be traced back to the ancient Greek period from the perspective of etymology. For the word "androgyny", in Greek etyma, "-andro" in androgyny refers to men while "-gyn" in androgyny refers to women, so in Greek, words "andros" and "gyne" refer to male and female respectively. The word "hermaphrodite" derives from Hermaphroditus in ancient Greek mythology-the son of Hermes (messenger god) and Aphrodite (love goddess) - according to Ovid, who, according to the legend, was an extremely handsome boy when born, and the unity with the water nymph Slamacis transformed him into an androgynous being. His name is the basis for the world hermaphrodite. Then, in the 19th century, Freud and Jung analyzed the phenomenon of Androgyny from a psychological point of view. Freud used psychoanalytic methods to draw the following conclusions: "For human beings, pure men or pure women can not be found either in the psychological sense or in the biological sense. On the contrary, everyone shows a mixture of their own characteristics and those of the opposite sex, showing a combination of initiative and passivity, regardless of whether the characteristics are in line with their own biological characteristics." (Freud, 2000: p. 79). Jung believes that people tend to be bisexual in both emotional and psychological aspects. He calls the feminine temperament "anima" existed in men both psychologically or physically, and calls the male temperament "animas" in women both psychologically or physically. "For thousands of years, a man has formed his anima prototype through 
constant contact with women, and a woman has formed her animus prototype through constant contact with men. Through thousands of years of living together and communicating with each other, men and women have acquired the characteristics of the opposite sex, which ensures the harmony and understanding between the two sexes." (Jung, 1987: p. 53). Freudian and Jung's interpretation of Androgyny revolves around the physiological and psychological possibilities of Androgyny in human beings from a scientific point of view.

Since the 1920s, the idea of Androgyny has been developed again, and it has become an important concept of feminist criticism. Virginia Woolf, the British female writer, first introduced Androgyny, as a concept, into the literary criticism. In 1928, Woolf formally proposed Androgyny as a literary theory in $A$ Room of One's Own. According to Woolf, what the theory of Androgyny pursues is a harmonious state between the male and female. First of all, she believes that the perfect state of a personality is supposed to share the characteristics of both sexes. Secondly, she extended the state of gender harmony in the individual to the social field, emphasizing the rationality and necessity of social division of labor. Finally, in Woolf's view, the concept of gender is vague and there is no absolute distinction between male and female, which breaks through limitations of former research from Freud and Jung, and breaks dual opposition model in the traditional gender, reaching a new realm of gender transcendence.

Androgyny is an ancient topic in the history of human civilization. The aesthetic pursuit of Androgyny has a long history, not only in the West, but also in ancient China. Ancient "Taoist" founder-Lao Tzu says in his Tao Te Ching, "One is child of the divine law. After one come two, after two come three, after three come all things. Everything has a bright and a dark side, co-existent in harmony." (Lao, 2003: p. 95). Yizhuan (an ancient Chinese philosophical book during the Warring States period) says, "Tao refers to alternating between Yin and Yang". It embodies the desire of human for the harmonious state between the sexes and the pursuit of the perfection of individual personality.

\subsection{Camp Taste for the Androgynous}

In early May, 2019, the Met Costume Institute's spring exhibition is all about camp: Notes on Fashion. What exactly is camp? Camp has deep historical precedent. The word "camp" first appeared in the year of Louis XIV, as a verb, it was in the novel of Moliere (1671), like "camp about on one leg. Struct like a comedy-king!” means a certain theatricality, impersonation and masquerade. In Victorian England, it became associated with queer subculture. In 1870, two male Londoners were arrested for, one of charges-impersonating a woman, Frederick Park (Fanny) who was one of the arrested man, once said "My campish undertakings are not at present meeting with the success which they deserve. Whatever I do seems to get me into hot water somewhere.". And then, "Camp" as a noun means actions and gestures of exaggerated emphasis in J. Redding Ware's Dictionary (1909), used chiefly by those who extremely pursue the individuality such as Oscar. Wilde. In 1964, It was to him that cultural art 
critic Susan Sontag dedicated her essay Notes on "Camp". In her essay, "camp" means the "love of the unnatural and of the exaggerated". She pointed that "I disapprove of cheap, shallow feelings. In naïve, or pure, Camp, the essential element is seriousness, a seriousness that fails". She wrote "to talk about Camp is therefore to betray it." (Li, 2015: p. 141). But once she talked about it, camp entered the mainstream where it continued to be redefined: Camp is the sizzle without the steak; camp is the heroism of people not called upon to be heroes; camp taste is a kind of love for human nature. camp is the extravagant posing; camp is a woman walking around in a dress made of three million feathers; camp is a holiday for consenting adults; camp is big business; camp is eternally hopeful; camp is a refusal to grow up; camp is generous; camp is happiness $(\mathrm{Xu}$, 2010: p. 67).

What's more, Sontag also argued that "Camp taste for the androgynous". According to her opinion, the most refined form of sexual attractiveness as well as the most refined form of sexual pleasure consists in going against the grain of one's sex. What is most beautiful in virile men is something feminine; what is most beautiful in feminine women is something masculine. That is so-called the androgynous temperament of cross-dressers which is also the topic that would be discussed in this paper. Therefore, according to Sontag, Cross-dressing culture can also be categorized as a kind of Camp culture.

\subsection{A Review of Androgyny Theory at Domestic and Overseas}

Although Androgyny is an ancient topic in China and the West, it was only after the 19th century that Freud and Jung's interpretation of Androgyny in psychiatry gradually made it the object of study in academia. With the development of the Western feminist movement, in the 1920s, British female writer Virginia Woolf formally introduced Androgyny into literary theory. In the 1970s, the concept of Androgyny attracted the attention of many Western feminist theorists: "Androgyny" as a relatively complete basic concept began in Heilbrun's Futher Notes toward a Recognition of Androgyny in 1974; in addition, in 1974, the Western feminist research journal Women's Studies includes many academic papers related to Androgyny. Bazin has compiled a large number of books on Androgyny from 13 perspectives, such as the history of Androgyny, Androgyny and the body, and two Western Monographs on Androgyny, Androgyny: The Opposites Within (1976) and Androgyny: Toward a New Theory of Sexuality (1977), June Singer, explains the basic concept of Androgyny in an interdisciplinary way. In the 1980s, Androgyny remained a hot topic for feminist scholars, such as Mary Vetterling-Braggin's article "Femininity", "Male temperament" and "Androgyny": A Modern Philosophical Discussion, which focused on Androgyny from the perspective of women's daily life. In the 1990s, the discussion of Androgyny by foreign scholars continued to be heated. In 1997, the Encyclopedia of Feminist Literary Theory included the term "Androgyny" for the first time. Pamela Starr Bromberg, the author of the entry, sees the link between An- 
drogyny and sub-cultural topics such as cross-dressing and transsexualism. In the 21st century, androgyny still stands in the course of the development of Western feminism. For example, in 2005, Hargreaves published Androgyny in Modern Literature, which continued to explore the relationship between androgyny and literary research.

However, in the domestic academic circles, searching "Androgyny" as a keyword on the CNKI, according to the information provided, since 1996, there have been 640 articles with Androgyny as a special research object. The research contents of this paper can be roughly divided into four categories from the perspective of gender studies. The first is to analyze literary works as literary theory; the second is as a concept of feminist theory; the third is to apply it to linguistic translation studies; and the fourth is to use it to analyze masculinity and femininity. Among them, there are 535 articles which regard Androgyny as a literary theory. For example, scholar Leng Dong, has made a relatively complete compilation in his article A Summary of the Application of Androgyny in Literature. Through the analysis of transvestite image from the perspective of androgyny, this paper can be classified into the fourth category of research on masculinity and femininity. Among them, Li Xianglin, a scholar of Sichuan University, has published many articles on gender studies, such as "Male Women", Cultural Identity on the Eastern and Western Deduction of Mulan's Story, Views on Nandan Performance Art in Chinese Opera and Cross-Dressing Art on the Stage, etc., which discuss and analyze the androgynous temperament of cross-dressers.

In short, compared with overseas academics, we can find that the domestic academia started the study of Androgyny later and the number of literatures is relatively small, and there is no monograph on the concept of Androgyny in detail (Wang \& Ma, 2017: p. 119). For a long time, the concept of androgyny is an important landmark term in feminist theory at home and abroad, but the vast majority of the articles focuses on the analysis of literary works, so there is still a lot of space for improvement and expansion on researches of male and female temperament with androgyny theory, which is the reason why this article chooses this topic to further explore.

\section{Androgyny in Cross-Dressers}

On the one hand, the transgender behavior caused by cross-dressing can break the traditional dual Gender Antagonism pattern constructed by social culture for a long time, which is vivid and carnival; on the other hand, the gender ambiguity caused by cross-dressing is often criticized and questioned by people, and accompanied by certain physiological and psychological costs, it is risky and dangerous. As Judith Butler, a well-known American gender scholar, pointed out in an interview, when a person lives within the existing rules, he often does not need to defend, but when he goes beyond the norms, he is challenged. Therefore, this article will objectively discuss and analyze cross-dressing from the perspective of Androgyny from the positive and negative aspects of gender cross-border 
behavior.

\subsection{The Great Revelry of Androgyny}

Psychologists Freud and Jung pointed out that human beings have both the physiological and psychological characteristics of androgyny-everyone is androgynous-and their emotions and mentality always have been both gender-oriented. The gender ambiguity of both masculinity and femininity in cross-dressers also embodies the ancient Chinese thought of pursuing the opposition while maintaining harmony between Yin and Yang. In the ancient Chinese love story of Liang Shanbo and Zhu Yingtai, besides breaking through the moral shackles of feudal forces on women to a certain extent, Zhu Yingtai's beautiful and handsome appearance after hermaphroditism also has an ideal and aesthetic expression both on the theatre stage and in the novel text. In the long process of building feudal culture, the gender-separated cultural order forms an interesting contrast with the Yin and Yang in artistic interpretation.

"Androgyny" points to an ideal perfect state beyond reality in artistic aesthetics, and radiates a new, multi-level and more exquisite aesthetic enjoyment on the basis of reconciling the beauty of both sexes. The hypothetical nature of Androgyny blurs the boundaries of the barriers between the sexes to the greatest extent, and makes it easy to pretend to be a magical passage through which the gender traverses quickly (Li, 2007: p. 4). Behind the gender revelry whistled out by the double hypothesis of identity identification and artistic techniques, it is a brilliant upsurge of real human gender liberation. "The transvestite to cross gender segregation contains carnival power, which will stimulate the struggle and remodeling of segregation and matching of gender and sexual orientation in the process of carnival transsexuality." (Bian, 2006: p. 52). Zhu Yingtai unexpectedly meets the real right one while infiltrating among young men in white robe to study the knowledge of country and world; Hua Mulan, who should have been waiting in the boudoir to be betrothed, resolutely disguises herself as a man to take the father's place in the conscription army when finding no one could solve the crisis the family is confronted with because she is not a male. Since, she doesn't like to powder the face but likes to face the powder; In Chinese Huangmei opera Emperor's Female Son-in-law, there is a line: I left home to save my husband, unexpectedly I became No.1 in Emperor's list after taking the imperial examination, which made me extremely surprised and excited when with official crown with the flower. Among which, Feng Suzhen, emperor's female son-in-law in red robe, could be seen extremely proud of her success when in the list, and even her feminine softness and shyness couldn't conceal her gallant makings. Another line, such as: I have been to the banquet for the successful newly candidate of the imperial examination (Note: Qiong Linyan (banquet), was a banquet for the new successful newly candidate of the imperial examination, which began in the Song Dynasty). I have also ridden through the street for public parade, showing glory (Note: In Ancient China, the Number One Scholar was given to 
ride around the streets in front of the Palace to show his glory). I was being complimented as handsome, and in fact, it is disguised-describes fully the delight sense of the Emperor's Female Son-in-law on stage after cross-dressing for male identity.

In fact, this exciting journey across the genders fully expresses the psychological and ethical release of the aphasic ancient women, so that the ideal legendary story still has extraordinary artistic charm on the stage of drama. On the one hand, the gender form under ethical restriction maintained the stability of feudal monarchy, on the other hand, the beauty of gender shuttle between men and women shines brilliantly in the field of culture and art. Hua Mulan, Zhu Yingtai and Feng Suzhen stepped into the space completely belonging to men with their heads held high, and also breaking into the hierarchical feudal society with the patricentric society as the core. The dual cross-dressing of physiology and psychology made it easy for them to be assigned to natural rights and identity of men. It is undeniable that these female roles all contain more or less masculinity, which, in ancient art aesthetics, points more to a kind of good personality or quality. Men's clothes and masculinity can quickly make a female actor become one that can't be distinguished from the real man, but in fact, it is not only the stereotyped appearance on the stage that really confuses the public, instead, the fundamental reason that the audience believe it lies in the presentation of the inner personality of these women-the transformation of gendered appearance from the inside to the outside makes them live on the stage. Courage and determination of Hua Mulan, rebellious intelligence of Zhu Yingtai and luck and talent of Feng Suzhen are what men aspire and desire for in ancient time. Above all, Androgyny could be presented to us so truly and directly in terms of the female role disguised as a man. This is idealistic state for hermaphrodite with fine condition of the charisma of both men and women.

\subsection{The Dangerous Boundary of Androgyny}

The magic effect of cross-dressing does not lie in the direct change of physiology and psychology, but lies in the fact that it achieves the transformation of genders through the feedback effect of the others. In other words, transvestite is not about turning a man into a real woman, or a woman into a real man, but about the belief of others. When people believe that an illusory image is expressed by the gender after changing clothes, this belief is mixed with the understanding and identification of the real gender of the person. The viewer not only knows the truth of the facts, but also feels confused and absent-minded to a certain extent. This genuine and subtle gender state in acting is the charm of androgyny, and this is where the danger exists.

Androgyny is not a simple and crude combination of masculinity and femininity. It is not a random mixture of gender characteristics, nor a perfect combination of prominent advantages of both sexes. What It presents is a unique aesthetic taste, which is neither replaceable nor replicated. For example, Cheng 
Dieyi, played by Zhang Guorong in the classic film Farewell My Concubine, is a representative figure in the concept of androgyny. This character who can't be a real man or a real woman lives in the eternal artistic life forever. His fascinating and charm-irresistible appearance on the stage, above all, his beauty completely abandons and crushes the cold concept of gender indication. His magnificent beauty is deposited on the short and noisy stage with a deep-rooted Lyric in the heart of people. Here, he is Yang Yuhuan, who always needs another drink to relieve her depression. When he was her, she freely shuttled back and forth in tens of millions of years. She expressed the subtlety and mystery of the relationship between men and women. She is the goddess of beauty on earth.

However, when she was him, the son of a prostitute, sent to the theatre troupe from childhood to beg for living. Therefore, he must be cut off the sixth finger, which is physiologically incumbent castration and damage, and the rough stereotyping and irreversibility of cross-dressing as well. It seems that the character's psychological struggle is so painful and sad. "I am born a boy, not a girl". The severe defense and struggle with extremely grief is a long and crucial step for him. The beautiful female costumes on Cheng Dieyi are easy to wear, but the road to becoming a woman is full of thorns. The more natural his posture of cross-dressing performance on the stage is, the more cruel is the mental and physical struggle between both sex. Therefore, androgyny is in fact an ideal yet unsought state. The combination of men and women's life experience take root in one's soul. Behind his appearance on stage in gorgeous clothes, he suffered a completely change in physiology and psychology. So he became her, and she lives in his real life forever, in a drama that never ends. When he finally made it sense, the play ended. Here is the sad element of androgyny, which is irreversible after the reconciliation of the two sexes, the paradoxical chaotic state, the enchanting moment, the cost of life, which is close to the double betrayal of the soul and the body. When he comes on stage in a gorgeous and beautiful costume, beauty will exist forever. Androgyny may naturally carry a certain spiritual cleanliness, it is not simply relying on the image of cross-dressers, such a transformation is difficult to convince others, and more difficult to complete themselves. Just like the case in Japanese Takarazuka Revue Company, when underage women is required to represent men, almost all of its audiences are women. Part of the reason why it is difficult for them to be recognized by male audience is that the process of transformation of such women into men is actually very flat, which is just to satisfy women's fantasies for the ideal men at the cost of divorcing from the real and more powerful content. In Visual Pleasure and Narrative Cinema, Laura Marvell proposed a male pleasure viewing mode-the audience is infatuated with similar male images. That is to say, male audiences can indirectly grasp the right by identifying with male images and bringing themselves into the male power of male images. However, in the view of Japanese Takarazuka Revue Company performance, the male role played by actresses makes it impossible for male audiences to successfully project their vision on 
male role and obtain pleasure identity, because the long-term cultural practice of society has already planned or defined the respective characteristics of male and female temperament, which is a safe area for the subject to be recognized, but the feminine temperament mixed into the body of male roles on the stage is not in this safe area, so the implied social condemnation and punishment will cause the psychological discomfort of male audiences (Shao, 2015: p. 101). In short, the change of gender identity caused by cross-dressing often comes with a physical and psychological cost to some extent.

\section{Conclusion}

The coexistence of beauty within masculinity and femininity in cross-dressers brings the ultimate aesthetic pleasure; at the same time, it also confuses the subject and the audience's perception of the true gender identity. Under enjoying the sexual beauty, it also wanders on the dangerous edge of gender out of control. The brilliant cross-dressers on the stage live in the eternal artistic life, who almost perfectly coordinate and balance the totally opposite two gender forms. This originates from the mysterious magic of changing clothes physically. By changing the outer symbol of the wearer's clothes, they easily surpass the gender boundary between the two sexes, and magically breed the touching aesthetic of androgyny.

The theory of Androgyny has a strong cultural influence on the discussion of gender research. By analyzing the characters of typical cross-dressers in theatre, film and literary works, this paper studies Cross-dressing culture, and at the same time expands the cultural radiation of Androgyny theory and Camp theory, which can be used for reference in breaking the traditional gender model of dualistic opposition and pursuing gender harmony, which provides a new direction for other scholars for the further research. However, the discussion of Cross-dressing as one of the gender issues is an extremely complex and changing process, which should be examined with a dynamic and open attitude, which, therefore, requires more researches and discussions in the future.

\section{Conflicts of Interest}

The authors declare no conflicts of interest regarding the publication of this paper.

\section{References}

Bian, J. (2006). 性别越界的狂欢——华语电影中的“易装”审美 [The Carnival of Transcending Gender: Aesthetic Appearance of "Cross-Dressing" in Chinese Films]. Forum of Arts, No. 11, 52-57.

Freud (2000). 性欲三论 [Three Essays on the Theory of Sexuality] (p. 79). Beijing: International Cultural Publishing Company.

Gao, Y. (2004). 戏剧中的男扮女装和女扮男装现象 [The Phenomenon of Cross-Dressing in Chinese Dramas]. Journal of Guizhou University (Art Edition), 18, 65-69. 
Jung (1987). 荣格心理学入门 [A Primer of Jungian Psychology] (p. 53). Hong Kong: Joint Publishing.

Lao, Z. (2003). 道德经 [Dao De Jing] (p. 95). Beijing: Higher Education Press.

Li, W. S. (2015). 关于坎普的再思考一一从“关于坎普的札记”到坎普电影 [Reflections on Camp: From Notes on Camp to Camp Films]. Theoretical Studies in Literature and Art, 34, 139-147.

Li, X. L. (2007). “雄化女性”、文化身份及其他一一兼谈木兰故事的东西方演绎 [“Male Women”, Cultural Identity on the Eastern and Western Deduction of Mulan's Story]. Nankai Journal, No. 4, 7-13.

Shao, Z. Z. (2015). 试探日本宝塚舞台上的易装形象 [A Tentative Study of the Cross-Dresser Images on the Stage of Takarazuka Revue Company]. Drama Home, No. $1,102-104+112$.

Wang, Z., \& Ma, X. (2017). 国内外西方女性主义理论中“双性同体”概念的研究述评 [A Review of the Research on the Concept of Androgyny in Western Feminist Theories at Home and Abroad]. Journal of Chinese Women's Studies, No. 3, 113-122.

$\mathrm{Xu}$, B. (2010). 扮装政治、弱者抵抗和“敢曝(Camp)美学” [Disguise Politics, Resistance of the Weak and "Camp Aesthetics"]. Theoretical Studies in Literature and Art, No. 5, 61-69. 